\title{
AVALIAÇÃO DOS EFEITOS DE DESCONTAMINANTES AMBIENTAIS USADOS PARA CORONAVÍRUS SOBRE ESPÉCIES AQUÁTICAS
}

\author{
Millena de Lima Ribeiro - CEUB, PIC/PIBIC COVID-19 CNPq, aluna bolsista \\ millena.lima@sempreceub.com \\ Heloisa Castro de Aguiar - CEUB, PIC/PIBIC COVID-19 CNPq, aluna voluntária \\ heloisa.caguiar@sempreceub.com \\ Eduardo Cyrino de Oliveira Filho - CEUB, professor orientador \\ eduardo.cyrino@ceub.edu.br \\ Darlan Quinta Brito - UnB, colaborador \\ darlan_aguia@yahoo.com.br
}

A ecotoxicologia é a ciência responsável pelo estudo dos efeitos adversos das substâncias químicas sobre os ecossistemas. Nesse contexto, ensaios ecotoxicológicos têm sido utilizados com as principais ferramentas para avaliar esses efeitos sobre as espécies vivas. No Brasil, com a pandemia de covid-19, várias cidades utilizam produtos químicos desinfetantes para descontaminação de ambientes externos, incluindo as ruas públicas. Todavia, esses agentes químicos desinfetantes tendem a escoar pela drenagem urbana, pelas águas pluviais ou pelo esgoto e atingir os recursos hídricos. Nesse contexto, o objetivo deste trabalho é avaliar e apresentar os efeitos adversos do álcool 70\%, da marca Zelle+, e do hipoclorito de sódio, da marca QBoa, na imobilidade de uma espécie planctônica e na sobrevivência de uma espécie bentônica, ambas de água doce. Para isso, foram realizados ensaios ecotoxicológicos agudos com o microcrustáceo Ceriodaphnia dubia e o gastrópode Biomphalaria glabrata. Os métodos de ensaio seguiram os padrões da ABNT para $C$. dubia e de trabalhos publicados para $B$. glabrata. Os resultados obtidos mostraram que, após 24 horas de exposição, o microcrustáceo $C$. dubia foi mais sensível a ambas as substâncias, com CEs50 de $0,45 \%$ e $0,0000024 \%$, enquanto o caramujo $B$. glabrata se mostrou mais resistente com CLs50 de 33,63\% e 0,02\% para o etanol e para o hipoclorito de sódio, respectivamente. Esses dados evidenciam que os produtos apresentam efeito tóxico agudo para espécies aquáticas testadas em concentrações bem abaixo das aplicadas no ambiente e, desse modo, devem ser utilizados com prudência, buscando evitar a possibilidade do escoamento superficial.

Palavras-Chave: recursos hídricos; contaminação; escoamento superficial; ecotoxicologia. 